Military Technical College

Kobry Elkobbah,

Cairo, Egypt

April 19-21,2016

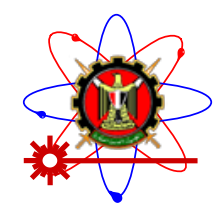

$8^{\text {th }}$ International Conference on Mathematics and Engineering Physics (ICMEP-8)

EM-5

\title{
DYNAMICS OF SUSPENDED SOLIDS IN DOWNWARD TURBULENT AIR FLOW THROUGH SUDDEN EXPANSION PIPE
}

\author{
W. A. El-Askary* ${ }^{*}$ I.M. Eldesoky**, O. Saleh ${ }^{* *}$, S. M. El-Behery* and A.S. \\ Dawood $^{* *}$
}

\begin{abstract}
A method with hybrid scheme is used to simulate turbulent gas-solid flow through sudden expansion pipe. The present developed code introduces good results in view of comparisons with available experimental data. This encourages the authors to extend the theoretical work considering different parameters. The effects of solid-particles on downward turbulent-air flow through the sudden expansion are simulated using Eulerian-Lagrangian approach. Reynolds averaged Navier Stokes equations associated with standard k- $\varepsilon$ turbulence model are used with four-way coupling between the two phases. The separation size is discussed under different effects including: particle sizes, mass loading ratios, area ratios and Reynolds numbers. The computational results indicate that the finest particles can increase the separation bubble size.
\end{abstract}

\section{Keywords:}

Gas-solid flow; Sudden-expansion; Eulerian-Lagrangian; Separation; Reattachment length

\section{Introduction}

_The separated flows downstream the step wall of a sudden-expansion pipe are frequently encountered in technical applications, including many engineering and natural processes like combustion chambers used in aeroplanes, power plants and engines as well as cyclone separators and dust collectors. Sound understanding of the physics of two-phase flow and

\footnotetext{
*Mechanical Power Engineering Department, Faculty of Engineering, Menoufiya University, Shebin El-Kom, EGYPT

** Basic Engineering Science Department, Faculty of Engineering, Menoufiya University, Shebin El-Kom, EGYPT

${ }^{1}$ Corresponding author (Wageeh El-Askary), Tel.: +2-0100-5255817, +2-048-3486965; Fax: +2-048-2235695

Email address: wageeh_elaskary@yahoo.com\&Wageeh.Elaskary@sh-eng.menofia.edu.eg
} 
Military Technical College

Kobry Elkobbah,

Cairo, Egypt

April 19-21,2016

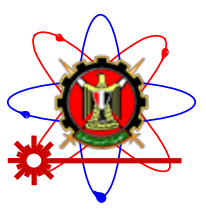

$8^{\text {th }}$ International Conference on

Mathematics and Engineering

Physics (ICMEP-8)

solution technique for gas-solid flow in sudden expansion problem are important prerequisites for studying two-phase flow behavior in complex geometries. Different researches were previously performed in such field considering the effect of different parameters. The studies included laminar and turbulent single or two-phase flows.

The effects of Reynolds number and area ratio (AR) on the velocity, streamlines and separation bubbles behind the step wall for laminar flow were studied in [1 to 6]. The review of Kumar et al. [7] also sheds light on such studies. The complexity of the turbulent flow has been solved using different methods such as, Reynolds Average Navier-Stokes equations (RANS) with a closure turbulence model, such as the standard k- $\varepsilon$ with good predictions to such field. This method is the widely used because low computer resources are needed in contrast to the other methods including large eddy simulation (LES) and direct numerical simulation (DNS). However, the turbulent single phase flow through sudden expansion and backward facing step was widely studied by many researchers [8 to 11].

Because the particle-laden flows are important in real life, many researches were devoted to understanding the particles dynamics in the fluid flow. Rapid progress in the theoretical and experimental studies of turbulence modulation has led to great understanding of the physics of particle-fluid turbulence interactions. Two-fluid model incorporating these advances for relatively dilute gas-dispersed flows containing high-inertia particles was established as Eulerian-Eulerian approach by Terekhov and Pakhomov [12]. In Eulerian-Lagrangian models, the turbulent gas flow was governed by Eulerian approach, whereas the particulate flow was governed by the Lagrangian trajectory equations. The Eulerian-Lagrangian approach was used by Mergheni et al. [13] and Pakhomov and Terekhov [14]. They found that the model can predict the particle laden flow successfully.

The effect of inter-particle collision was studied by Founti and Klipfel [15], Xiangli et al. [16] and Zhou et al. [17]. They concluded that the inclusion of particle-particle collision enhances efficiency of the model predictions. The dispersion of the particles in the separation bubble behind the step wall and the particles ability on entering or leaving the separation zone were studied by Hardalupas et al. [18].

Deguchi et al. [19] studied experimentally for gas-solid flows the loss coefficient of horizontal sudden expansion, while Tashiro and Tomita [20 and 21] studied the loss coefficient for the vertical downward and upward sudden expansions, respectively. They concluded that as a Richardson number increases the loss coefficient decreases for all orientations but for the vertical upward flows, the loss coefficient is higher than the other orientations. However, the studies did not include the effects of main parameters such as mass ratio and particles sizes on the separation size.

Marjanovic et al. [22] introduced analytical and numerical studies of the pressure recovery of gas flow, with or without solids. They concluded that the analytical 1D method can give accepted results compared with experimental and the numerical results without general conclusion. Gundogdu et al. [23] estimated equation for the pressure loss coefficient and the minor loss coefficient for turbulent gas-solid flow through a horizontal sudden-expansion pipe using different particles sizes. The study was based on slip velocity between the two phases. The computed loss coefficient was found in good agreement with the data of Marjanovic et al. 
Military Technical College

Kobry Elkobbah,

Cairo, Egypt

April 19-21,2016

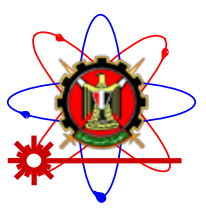

$8^{\text {th }}$ International Conference on Mathematics and Engineering Physics (ICMEP-8)

[22] and Deguchi et al. [19]. Yinpeng et al. [24] developed a theoretical study of local resistance coefficient with good prediction in view of the available actual losses.

However, complete understandings of the flow structure including its dynamics with different particle sizes or mass loading ratios have not been achieved. The mutual effects of the solids on the gas-phase are also an effective parameter that must be considered.

In the present study, a numerical code is developed based on Eulerian-Lagrangian approach to study gas-solid flow in sudden expansion pipe. The effects of aerodynamic forces and the space occupied by particles upon the particulate stresses are considered in the present model. The study includes the effects of flow Reynolds number Re, mass loading ratio MR, area ratio AR and particle diameter $D_{p}$ on the sudden expansion performance, including the flow separation and loss coefficients.

\section{Mathematical Model}

Two phase (particle laden) flow is numerically studied using Eulerian-Lagrangian approach. The continues-phase simulation is carried out by Eulerian equations, while the solid particles prediction is based on the trajectory method of Lagrangian equations.

\subsection{Continues phase model (gas phase)}

The general turbulent gas flow equations based on Reynolds-averaged Navier-Stokes equations (RANS) for steady axisymmetric flows are expressed in cylindrical coordinates as:

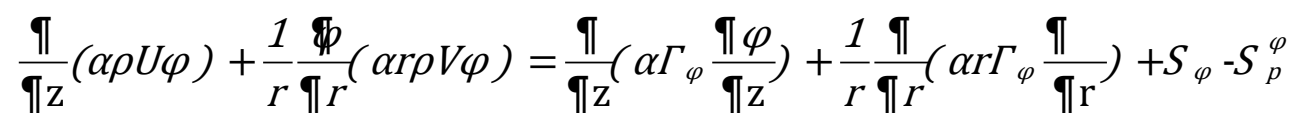

(1)

where, $\varphi$ is the generalized dependent variable, $\Gamma_{\varphi}$ is the transport coefficient, $S_{\varphi}$ is the source term of the continues phase, and $S_{p}^{\varphi}$ is the source term due to fluid-particles interaction. The meaning for each variable in the governing equation is given in Table (1).

Table(1) Variables included in the governing equations for the gas phase

\begin{tabular}{|c|c|c|c|c|}
\hline Conservation of & $\varphi$ & $\Gamma_{\varphi}$ & $S_{\varphi}$ & $S_{p}^{\varphi}$ \\
\hline Continuity & 1 & 0 & 0 & 0 \\
\hline Axial momentum & $U$ & $\mu_{\text {eff }}$ & $-\frac{\partial(\alpha p)}{\partial z}+\frac{\partial}{\partial r}\left[\alpha \mu_{e f f} \frac{\partial V}{\partial z}\right]+\frac{\partial}{\partial z}\left[\alpha \mu_{\text {eff }} \frac{\partial U}{\partial z}\right]$ & $\frac{1}{V_{c}} \Sigma F_{z}$ \\
\hline Radial momentum & $V$ & $\mu_{\text {eff }}$ & $-\frac{\partial(\alpha p)}{\partial r}+\frac{1}{r} \frac{\partial}{\partial r}\left[\alpha r \mu_{\text {eff }} \frac{\partial V}{\partial r}\right]+\frac{\partial}{\partial z}\left[\alpha \mu_{\text {eff }} \frac{\partial U}{\partial z}\right]$ & $\frac{1}{V_{c}} \Sigma F_{r}$ \\
& & & $-2 \alpha \mu_{e f f} \frac{V}{r^{2}}$ & \\
\hline
\end{tabular}


Military Technical College

Kobry Elkobbah,

Cairo, Egypt

April 19-21,2016 $8^{\text {th }}$ International Conference on

Mathematics and Engineering

Physics (ICMEP-8)

\begin{tabular}{|c|c|c|c|c|}
\hline $\begin{array}{c}\text { Turbulent kinetic } \\
\text { energy }\end{array}$ & $k$ & $\frac{\mu_{\text {eff }}}{\sigma_{k}}$ & $\alpha\left(G_{k}-\rho \varepsilon\right)$ & $S_{p}^{k}$ \\
\hline $\begin{array}{c}\text { Kinetic energy } \\
\text { dissipation rate }\end{array}$ & $\varepsilon$ & $\frac{\mu_{e f f}}{\sigma_{\varepsilon}}$ & $\alpha \frac{\varepsilon}{k}\left(C_{1} G_{k}-C_{2} \rho \varepsilon\right)$ & $S_{p}^{\varepsilon}$ \\
\hline
\end{tabular}

The turbulent kinetic energy generation term $G_{k}$ can be defined as:

$G_{k}=\mu_{t}\left[2\left[\frac{\partial U}{\partial z}\right]^{2}+2\left[\frac{\partial V}{\partial r}\right]^{2}+2\left[\frac{V}{r}\right]^{2}+\left[\frac{\partial U}{\partial r}+\frac{\partial V}{\partial z}\right]^{2}\right]$

(2)

$\mu_{\text {eff }}=\mu_{\mathrm{t}}+\mu$

(3)

and $\mu_{t \mu}=C \rho \frac{k^{2}}{\varepsilon}$

(4)

where $\mu_{e f f}$ is the effective viscosity and $\mu_{t}$ is the turbulence viscosity.

The model's constants are $C_{\mu}=0.9, \sigma_{k}=1, \sigma_{\varepsilon}=1.3, C_{1}=1.44$ and $C_{2}=1.92$ as used by Hamed [25].

\subsection{Solid phase model}

Using the Lagrangian approach, the solid particles are simulated by the trajectory method assuming the particles to be spherical in shape and rigid (non-deformed) during the particlewall and particle-particle interactions. The solution is performed using a finite number of trajectories (parcels) and in each trajectory a few number of particles with diameter $D_{p}$ is traced in a pipe with sudden expansion. The system of ordinary differential equations given by El-Behary et al. [26] is used to calculate the transitional velocities $u_{p}$ and ${ }^{v_{p}}$ as well as the angular velocity $\omega_{p}$ along the particle path.

$$
\begin{aligned}
& \frac{d \vec{Z}_{p}}{d t}=\vec{V}_{p} \\
& m_{p} \frac{d \vec{V}_{p}}{d t}=\vec{F}_{D}+\vec{F}_{S L}+\vec{F}_{L M}+\vec{F}_{G} \\
& I_{p} \frac{d \vec{\omega}_{p}}{d t}=\pi \mu D_{p}^{3}\left(0.5, \times \vec{v}_{f}-\vec{\omega}_{p}\right)
\end{aligned}
$$


Military Technical College

Kobry Elkobbah,

Cairo, Egypt

April 19-21,2016 $8^{\text {th }}$ International Conference on

Mathematics and Engineering

Physics (ICMEP-8)

where, $\vec{Z}_{p}$ is the particle position vector, $\dot{v}_{f}$ and $\vec{V}_{p}$ are the fluid and particle velocity vectors, $\vec{\omega}_{p}$ is the particle angular velocity vector, $m_{p}$ is the particle mass and $\left(I_{p}=0.1 m_{p} D_{p}^{2}\right)$ is moment of inertia.

The components of the forces acting on the particles are represented by $\operatorname{drag}\left(\vec{F}_{D}\right)$, shear lift $\left(\vec{F}_{S L}\right)$, Magnus lift $\left(\vec{F}_{L M}\right)$ and gravity $\left(\vec{F}_{G}\right)$, respectively and calculated as follows:

$\vec{F}_{D}=\frac{3}{4} \frac{\rho m_{p}}{\rho_{p} D_{p}} \mathrm{C}_{D}\left(\vec{v}_{f}-\vec{V}_{p}\right)\left|\vec{v}_{f}-\vec{V}_{p}\right|$

Where, $C_{D}$ is the drag coefficient calculated as given by Hamed [25].

$\vec{F}_{S L}=1.615 D_{p} \mu \operatorname{Re}_{S}^{0.5} C_{S L}\left[\left|\vec{v}_{f}-\vec{V}_{p}\right| \vec{\omega}_{f}\right]$

where, $\vec{\omega}_{f}=0.5\left(\nabla \times \vec{v}_{f}\right)$ is the fluid vorticity, $\operatorname{Re}_{s}=\rho D_{p}^{2}\left|\vec{\omega}_{f}\right| / \mu$ is the particle Reynolds number of the shear flow, and $C_{S L}$ is the shear lift coefficient representing the ratio of extended lift force to the Saffman force as given in [27]and[28].

$\vec{F}_{L M}=\frac{\pi}{8} \rho V_{r}^{2} D_{p}^{2} C_{L M} \frac{\vec{\omega}_{r} \times \vec{V}_{r}}{\left|\vec{\omega}_{r}\right| \cdot\left|\vec{V}_{r}\right|}$

where $\vec{V}_{r}$ is the local relative-velocity vector between fluid and particle velocity $\left(\vec{V}_{r}=\vec{v}_{f}-\vec{V}_{p}\right)$ and $\vec{\omega}_{r}$ is the relative angular velocity vector $\left(\vec{\omega}_{r}=\vec{\omega}_{f}-\vec{\omega}_{p}\right) . C_{L M}$ is the Magnus lift coefficient [15]and[29].

$$
\vec{F}_{G}=m_{p} \vec{g}\left[\frac{\rho}{\rho_{p}}-1\right]
$$

where $\vec{g}$ is the gravitational acceleration vector.

The actual velocity vector of the fluid $\vec{v}_{f}$ is computed from the mean fluid velocity vector $\vec{V}$ included in the fluid equation and the fluctuating velocity vector $\vec{v}^{\prime}$ due to the turbulence as given by El-Askary et al. [30]:

$\vec{v}_{f}=\vec{V}+\vec{v}^{\prime}$

$v^{\prime}=\zeta \sqrt{2 k / 3}$

assuming the fluctuating velocities are isotropic turbulence in which $u^{\prime}=v^{\prime}$ and $\zeta$ is a random number with zero mean and unity variance.

The $4^{\text {th }}$ order Runge-Kutta method is used to solve the ordinary differential equations in small time step known as the Lagrangian time step $\left(\Delta t_{L}\right)$. 
Military Technical College

Kobry Elkobbah,

Cairo, Egypt

April 19-21,2016 $8^{\text {th }}$ International Conference on

Mathematics and Engineering

Physics (ICMEP-8)

\subsection{Particle-wall collision}

The particle-wall collision is simulated considering the hard sphere model. The impact of the sphere on the wall can be adhesive impact or sliding impact. In the adhesive impact the particle stops sliding during the collision process, but in sliding impact, the particle continues to slide during the collision process. The governing equations for the particle-wall collision are given in [31 and 32].

\subsection{Particle-particle collision}

The particle-particle collision can happen in the domain by assuming a virtual particle in the domain and the actual moving particle in the domain. The virtual particle properties are assumed equal to the average properties of solid phase in the cell containing the particles see [33] and [34].

\subsection{Coupling between the two phases}

The source term $S_{p}^{\varphi}$ in equation (1) is the term responsible for linking the two phases. The momentum exchange term was proposed by Lun and Liu [29] as:

$\vec{S}_{p}^{V}=\frac{\beta \rho_{p}}{m_{p} N_{p}} \sum_{i=1}^{N_{t}} \vec{F}$

where, $N_{p}$ is the number of particles per unit time in the computational cell, $N_{t}$ is the total number of trajectories, $\beta$ is the particles void fraction and can be calculated by using trajectory method as in [30 and 34]:

$\beta=\sum_{\text {Traj }} \frac{N_{p} \Delta t_{L} V_{p}}{V_{c}}$

where $V_{c}$ is the cell volume and $\sum_{\text {Traj }}$ means summing over all trajectories passing through the computational cell.

From the particles void fraction, the gas void fraction can be calculated from:

$\alpha=1-\beta$

The source terms of turbulent kinetic energy and dissipation rate equations are given by Eghlimi et al. [35] as:

$S_{p}^{k}=2 k \frac{\beta \rho_{p}}{\tau_{p}}\left[1-e^{\left[-B_{k} \frac{\tau_{p}}{\tau_{l}}\right]}\right]$
$S_{p}^{\varepsilon}=2 \varepsilon \frac{\beta \rho_{p}}{\tau_{p}}\left[1-e^{\left[-B_{\varepsilon} \frac{\tau_{p}}{\tau_{l}}\right]}\right]$

with $\tau_{l}=k / \varepsilon$ and $B_{k}$ and $B_{\varepsilon}$ are constants taking the values 0.09 and 0.4 , respectively. 
Military Technical College

Kobry Elkobbah,

Cairo, Egypt

April 19-21,2016 $8^{\text {th }}$ International Conference on

Mathematics and Engineering

Physics (ICMEP-8)

\subsection{Boundary conditions}

For the inlet condition, gas flow velocity is assumed as $1 / 7$ th power law profile and the turbulent kinetic energy and its dissipation rate are assumed constant while, the particles velocity is assumed as constant value, depending upon the particles mass flow rate. For the solid walls, the no slip boundary conditions are assumed with wall-function approximation [36]. The particle-wall collision theory, discussed previously, is applied for the solids.

The symmetric boundary conditions are applied for all variables at the centerline. At the exit, the axial gas velocity is corrected to satisfy the mass balance. More details can be found in [36].

\subsection{Solution procedure}

The partial differential equations for the continuous phase are solved by finite volume discretization with hybrid scheme and using SIMPLE algorithm for pressure-velocity coupling. The ordinary differential equations for the solid phase are solved for each trajectory by fourth order Runge-Kutta method

\section{Results and Discussions}

\subsection{Validation of the numerical code}

The accuracy of the developed numerical code is first assessed through comparisons with the experimental results of Zhou et al. [17] using different grid resolutions $(302 \times 31,604 \times 62$ and $1206 \times 124$ ) in streamwise and radial directions, respectively) to choose the suitable resolution.

The case under consideration includes geometry of a sudden expansion pipe with upstream pipe radius $\left(R_{\text {in }}=0.025 \mathrm{~m}\right)$, downstream pipe of radius $\left(R_{\text {out }}=0.06 \mathrm{~m}\right)$ and length $(L=1 \mathrm{~m})$. The inlet gas mass flow rate of $212.4 \mathrm{~kg} / \mathrm{h}$, carries particles of $0.005 \%$ volumetric loading ratio with uniform particles diameter of $50 \mu \mathrm{m}$ and material density of $2500 \mathrm{~kg} / \mathrm{m}^{3}$. The geometry of the sudden expansion is considered to be vertical with downward flow.

Figures (1) to (4) are plotted for different streamwise positions after the step wall of sudden expansion reading $z / H=1.1,3.4,7$ and 14.1 , where $z$ is the position measured behind the step and $\mathrm{H}$ is the step height $\left(H=R_{\text {out }}-R_{\text {in }}\right)$.

Axial velocity profiles of the gas phase are computed for each grid and presented in Fig. 1. It can be seen from this figure that the model predictions agree well with the experimental data. In addition, the solutions of the finest grids $(1206 \times 124$ and $604 \times 62)$ are very close. Therefore, the resolution using $604 \times 62$ grid is considered and used for subsequent computations. The back flow behavior behind the step wall can be effectively predicted using the used turbulence model and resolutions. 
Military Technical College

Kobry Elkobbah,

Cairo, Egypt

April 19-21,2016

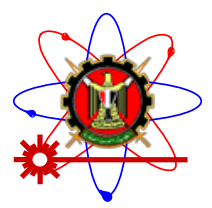

$8^{\text {th }}$ International Conference on Mathematics and Engineering Physics (ICMEP-8)

The predicted axial velocity of particles is compared with experimental data of [17] at different locations as shown in Fig. 2. The figure indicates that the present model can also predict the particle velocity in the separation region $(z / H \leq 3.4)$.The linearity of the turbulence model and spherical assumptions may be the main reasons for small differences. However, approaching the fully developed equilibrium case at $z / H=14.1$, the agreement between measured and predicted particles velocity is good.

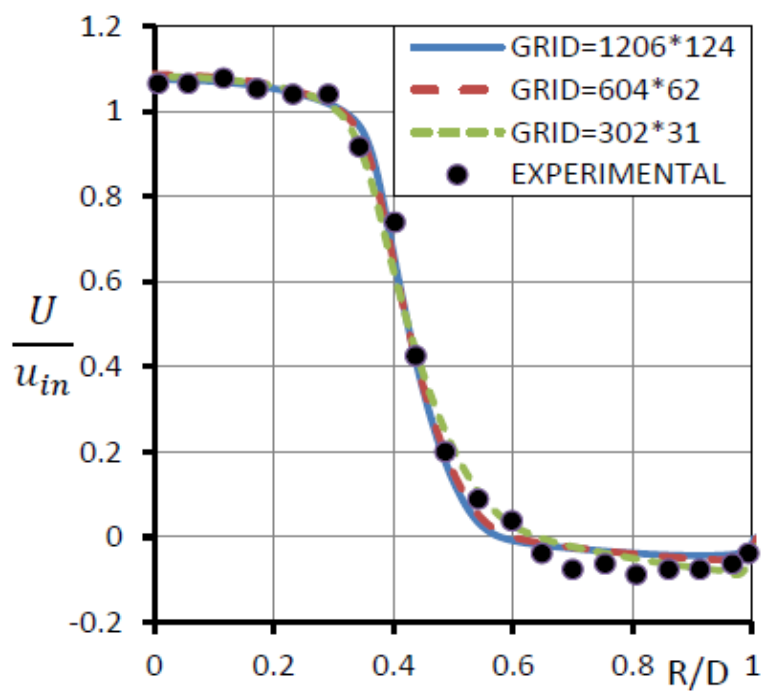

a) $z / H=1.1$

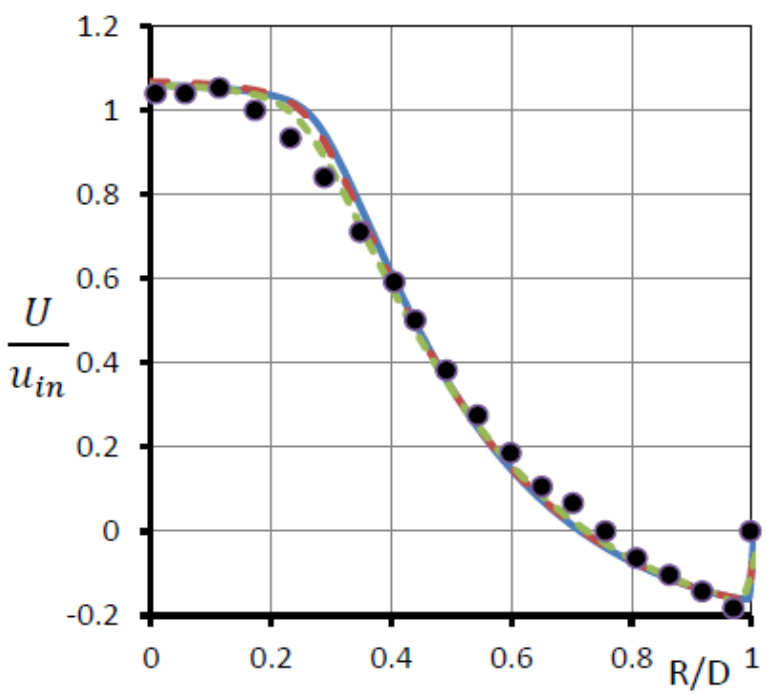

b) $z / H=3.4$

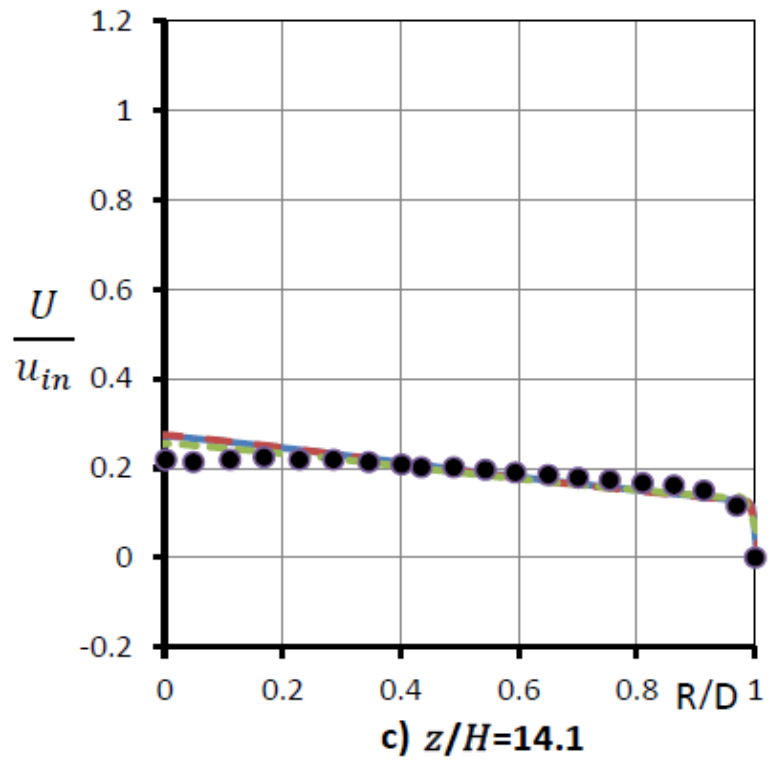

Figure (1) Comparison between computed mean axial gas velocities with experimental data of [17] at different streamwise positions for different resolutions 
Military Technical College

Kobry Elkobbah,

Cairo, Egypt

April 19-21,2016

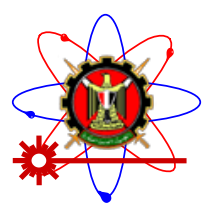

$8^{\text {th }}$ International Conference on Mathematics and Engineering Physics (ICMEP-8)

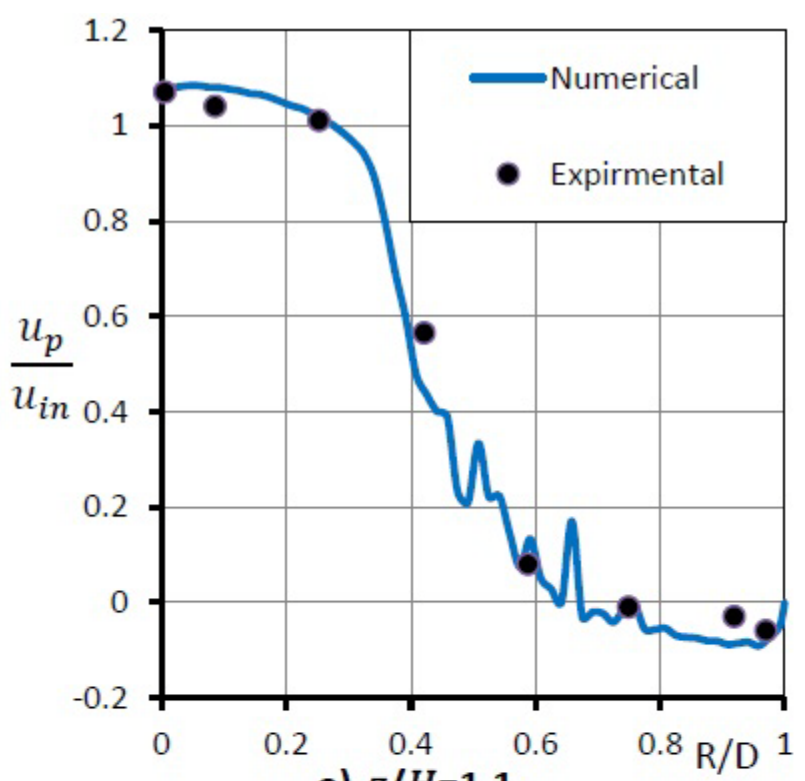

a) $z / H=1.1$

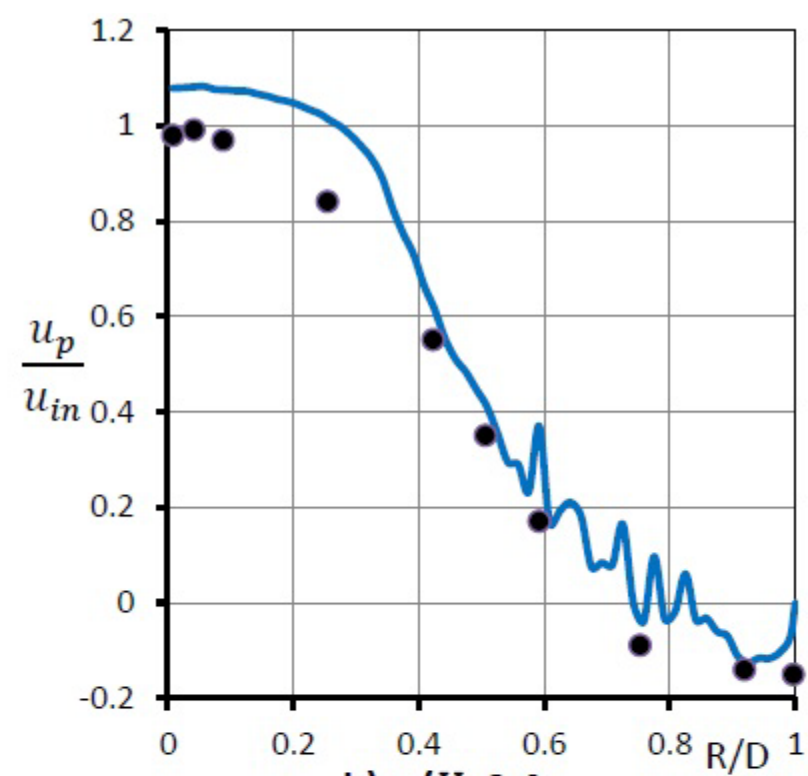

b) $z / H=3.4$

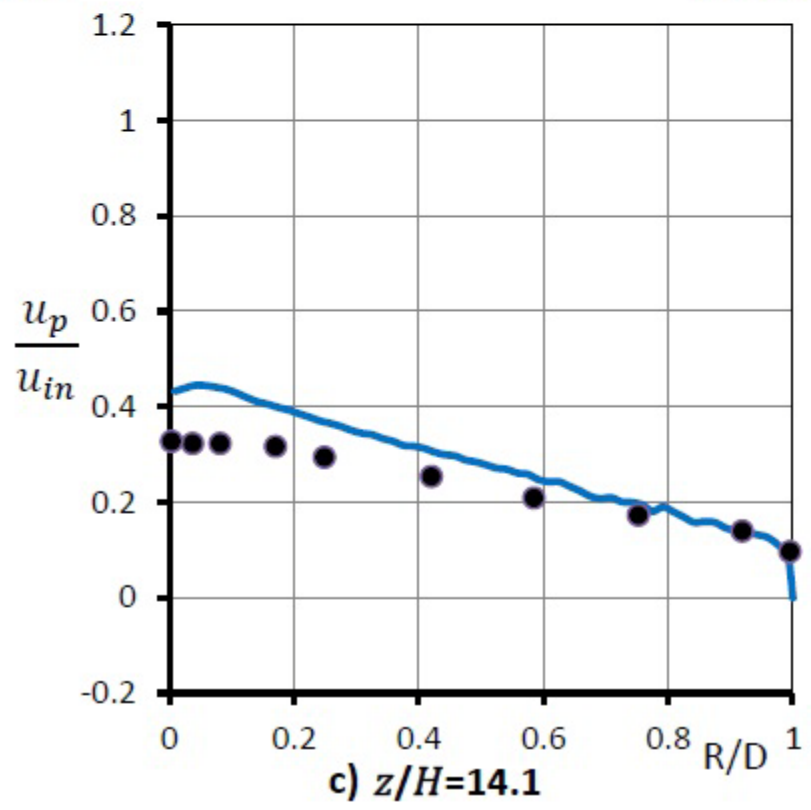

Figure (2) Comparison between computed axial particles velocity with experimental data of [17] at different streamwise positions

Comparisons between predicted and measured normal Reynolds stresses are shown in Figs. 3 and 4. Inside the separation region the model underpredicts the Reynolds stress in the axial 
Military Technical College

Kobry Elkobbah,

Cairo, Egypt

April 19-21,2016

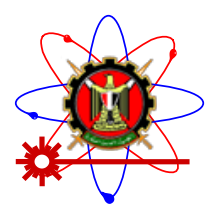

$8^{\text {th }}$ International Conference on Mathematics and Engineering Physics (ICMEP-8)

direction $\left(u^{\prime} u^{\prime}\right)$. This can be attributed to isotropic assumption inherent in the standard k- $\varepsilon$ model. The model predicts the last location profile at $z / H=14.1$ very well. In general, the developed model can predict the turbulent gas-solid flow through sudden expansion with accurate behaviour, which encourages the authors to extend the theoretical study.

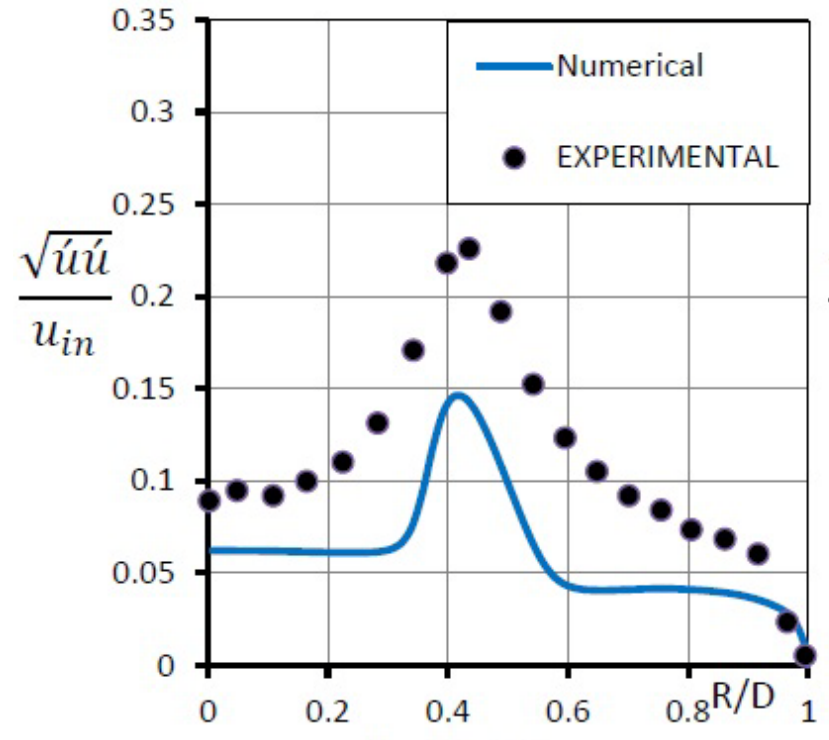

a) $z / H=1.1$

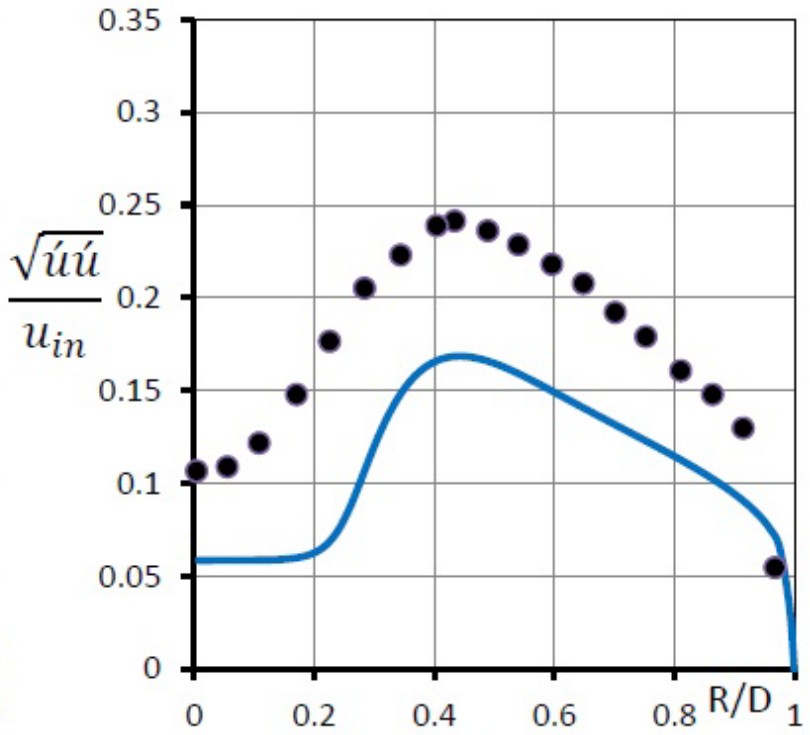

b) $z / H=3.4$

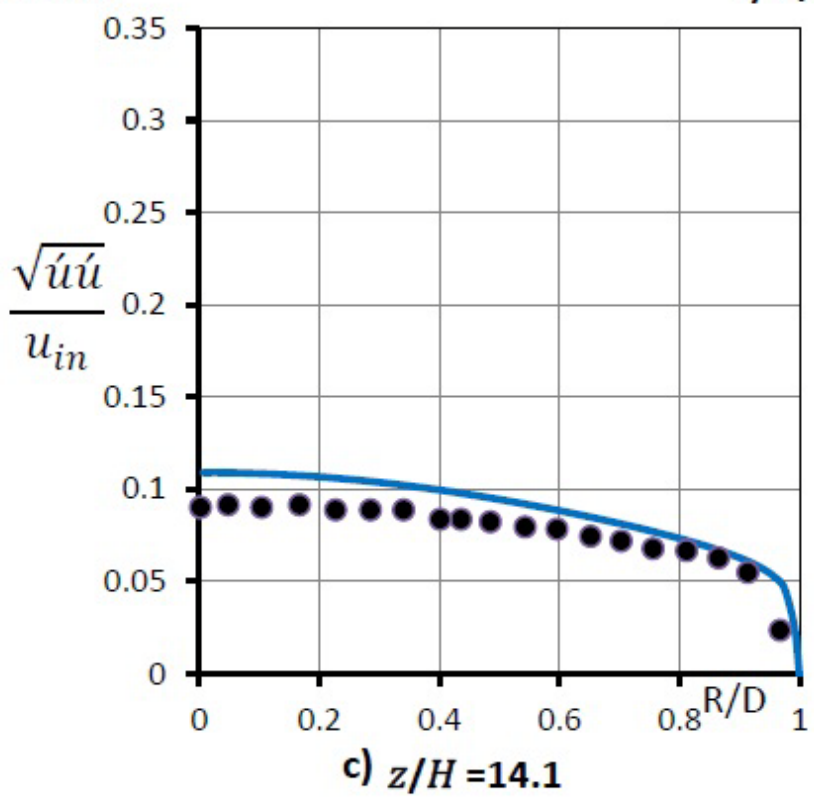

Figure (3) Comparison between computed square root of axial-axial fluid fluctuating velocity with experimental results of [17] at different streamwise positions 

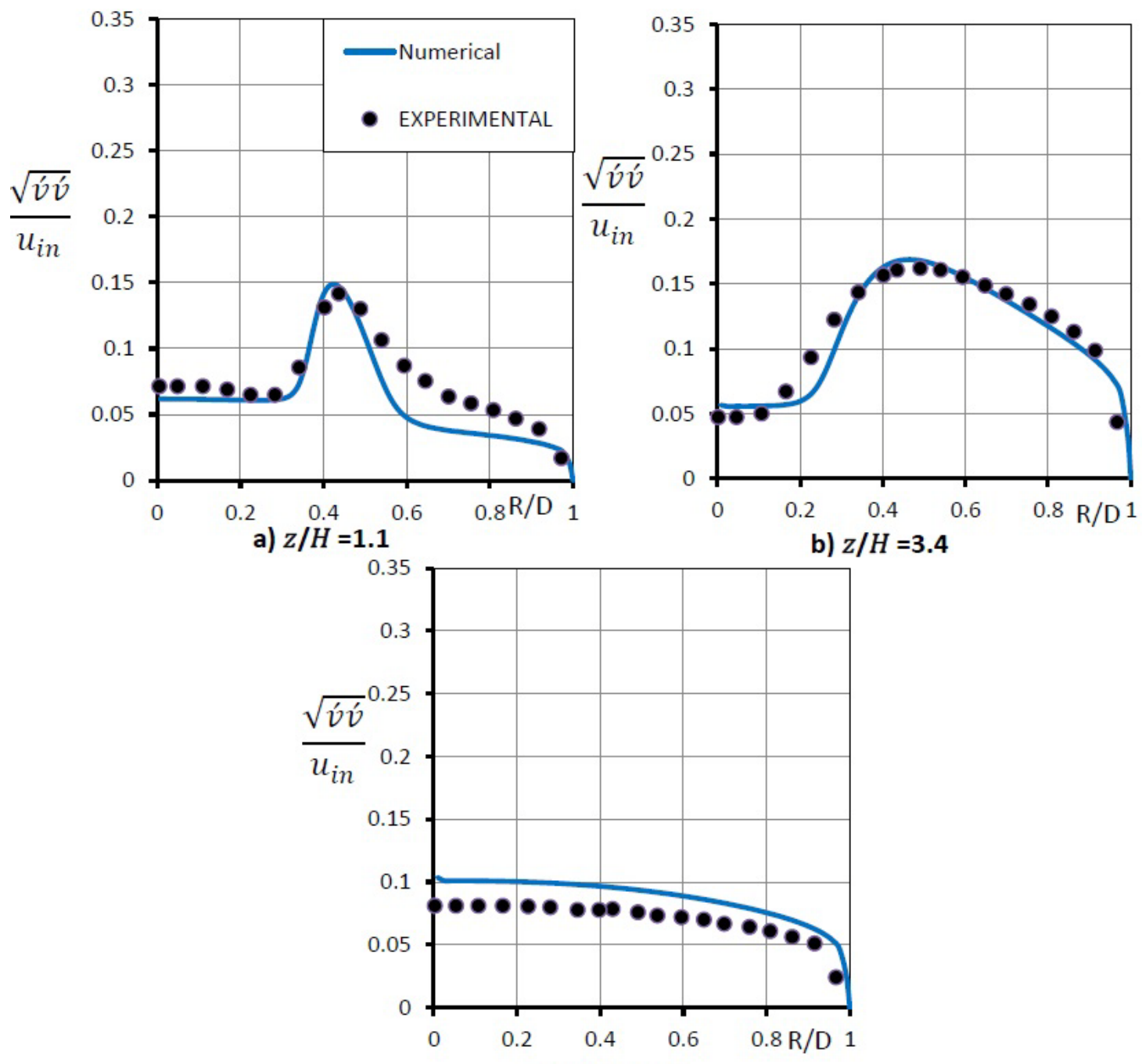

c) $z / H=14.1$

Figure (4) Comparison between computed square root of the radial-radial fluid fluctuating velocity with experimental results of [17] at different streamwise positions

\subsection{Separation and reattachment}

As reported by El-Askary et al. [30] and El-Behery and Hamed [37], there are two definitions to the separation bubble. The first one is based on the dividing streamline while the second is based on the position where the axial velocity crosses zero (i.e., the region of reverse flow). According to [30] the reattachment point is the point at which the wall shear stress is zero. The reattachment length (the distance between the step wall and the reattachment point) is examined for different particle sizes and mass loading ratios in Fig 5. It can be seen from this figure that the size of separation bubble increases as the particle size decreases and mass loading ratio increases based on the particles in the upstream pipe are charged with momentum 
Military Technical College

Kobry Elkobbah,

Cairo, Egypt

April 19-21,2016

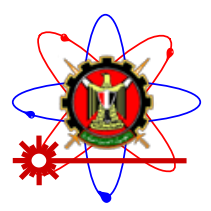

$8^{\text {th }}$ International Conference on Mathematics and Engineering Physics (ICMEP-8)

from the gas phase. After passing through the step wall of sudden expansion pipe the particles deceleration rate is less than that of gas phase due to the high inertia of the particles. The momentum of the particles is transferred back to the air flow. This momentum exchange enhances the turbulence energy of gas phase. The momentum exchange rate increases as the mass loading ratio increases and this is due to the increased number of the particles in the flow. As well as for the same mass loading ratio the number of particles in the flow increases as particle size is going down. Therefore, the momentum rate increases as the particle size decreases.

The smaller particles as well as the higher mass loading ratio energize the mean gas stream, which in turn increases the size of separation bubble.

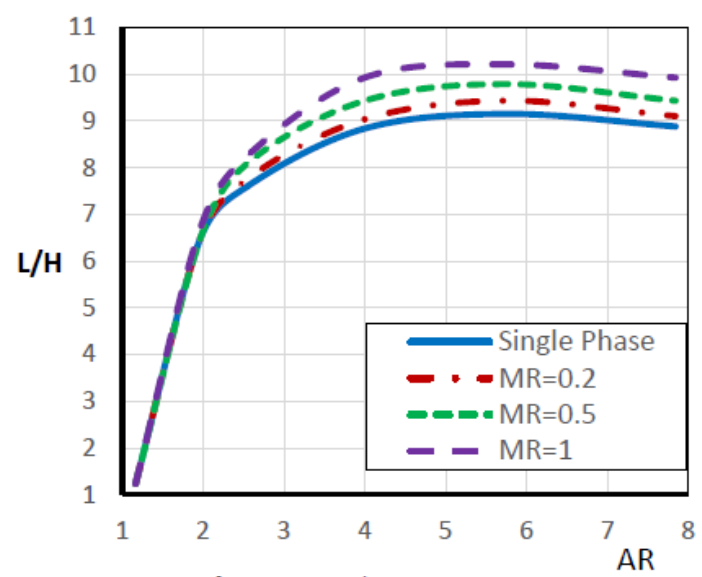

a) $D_{p}=50 \mu m$

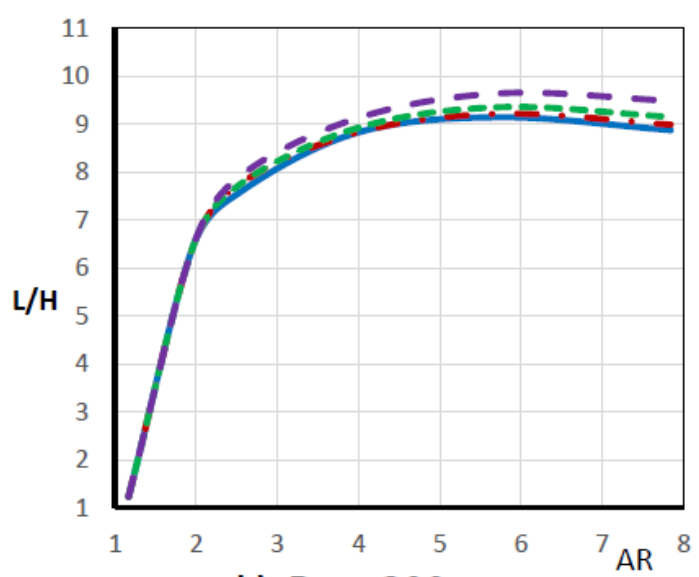

b) $D_{p}=200 \mu m$

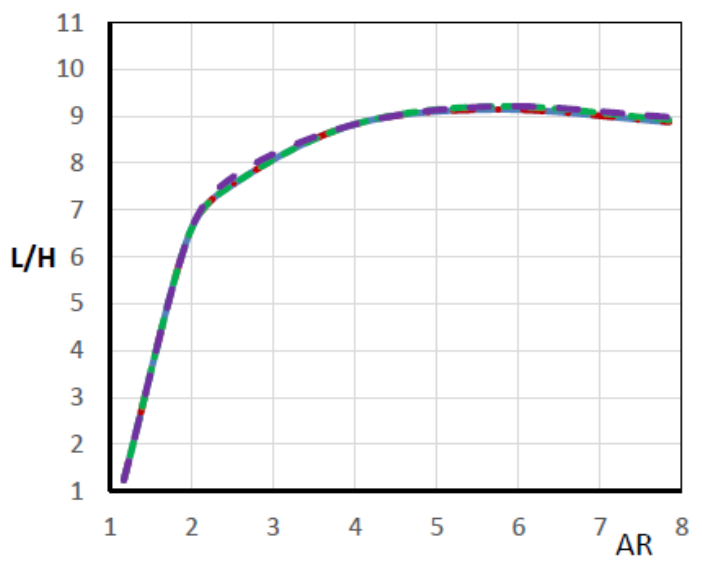

c) $D_{p}=600 \mu m$

Figure (5) Effects of mass loading ratio on separation bubble length for different particles sizes and area ratios 
Military Technical College

Kobry Elkobbah,

Cairo, Egypt

April 19-21,2016

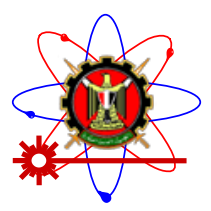

$8^{\text {th }}$ International Conference on Mathematics and Engineering Physics (ICMEP-8)

Depending on the particle size, the particle dispersion behind the step wall changes strongly as shown in Fig. 6. The difference in behavior is due to the particles entering and leaving the separation zone where there are four parameters controlling that process as mentioned by Hardalupas et al. [18]:

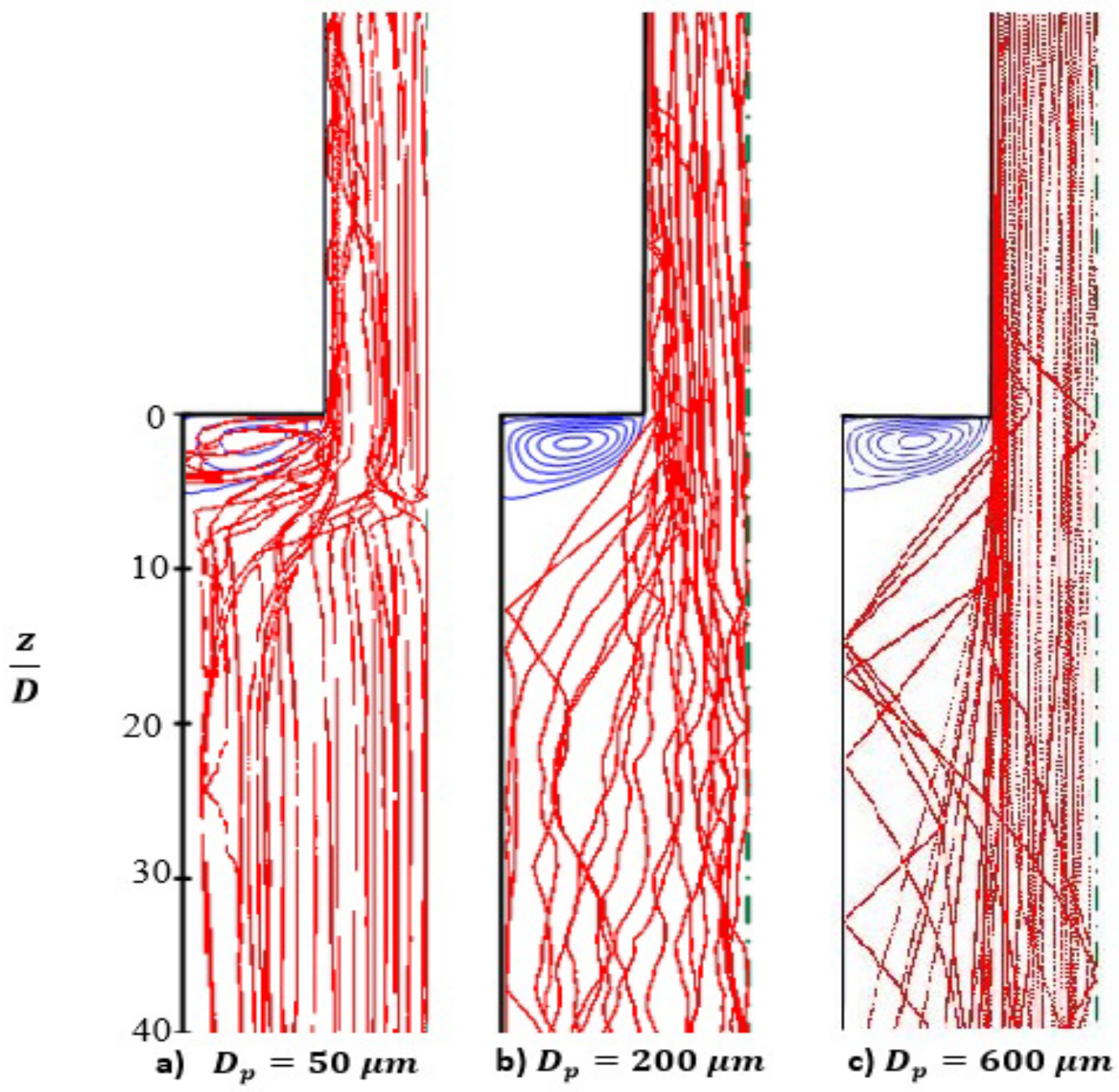

Figure (6) Effects of particle size on the particles trajectory at $\quad\left(\mathrm{Re}=2 \times 10^{4}, \mathrm{MR}=1.0\right.$

$$
\text { and } A R=5.76 \text { ) }
$$

First, the particles transit time across the reattaching length (the ability of particles to respond to the air turbulence) represented by the transit Stokes number $S t_{t r}=T_{t r} / \tau_{p}$, where $T_{t r}$, is the particle transit time between the step and the mean reattachment point. The transit time can be calculated by relation, $T_{t r}=L / 0.5\left(U_{U}+U_{r}\right)$, where $L$ is the reattachment length, $U_{U}$ and $U_{r}$ are the center line velocity at the step wall and at the end of the separation bubble, respectively. 
Military Technical College

Kobry Elkobbah,

Cairo, Egypt

April 19-21,2016

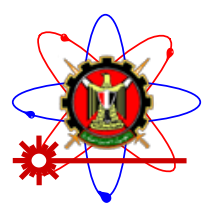

$8^{\text {th }}$ International Conference on

Mathematics and Engineering

Physics (ICMEP-8)

Second, the large eddy Stokes number based on the ratio between the characteristic timescale of the large eddies to the particle relaxation time $\left(S t_{e}=H / U_{o} \tau_{p}\right)$, where, $U_{o}$ is the air velocity in the large tube. Third, the centrifugal force of the particles which entered in the separation bubble and this force acts against the particles desperations on the recirculation zone. Fourth, the gravity force acts to leave the particles from the separation bubble.

The Stokes number for the case of $\mathrm{Re}=2 \times 10^{4}$ is calculated for different particles diameters at $M R=1$ and given in Table(2). The particles can enter to the separation zone when both $S t_{t r}$ and $S t_{e} \geq 1$ as shown in Fig. $8\left(D_{p}=50 \mu \mathrm{m}\right)$, while the outward force of the particles inside the corner eddy due to curved streamlines and the particles-gravity force of large-size particles play a mean role in particles exit from the separation zone.

Table (2) Stokes numbers for different particles diameter at $\mathrm{Re}=2 \times 10^{4}$ and $M R=1$

\begin{tabular}{|c|c|c|}
\hline$D_{p}(\mu \mathrm{m})$ & $S t_{t r}$ & $S t_{e}$ \\
\hline 50 & 84.87994 & 1.537627 \\
\hline 200 & 5.895576 & 0.086433 \\
\hline 600 & 0.570633 & 0.010244 \\
\hline
\end{tabular}

As noticed previously, the size of separation bubble is reverse proportion to the particle size as the smallest particle diameter can enter the separation zone easily where the interaction between the gas and the particles plays a great role in this process.

As shown below the turbulence kinetic energy is great for the smallest particle diameter, so that the small particles have a transient time enough to inter the separation bubble than the biggest ones. The large eddy Stokes number depends mainly on the particle relaxation time (the step height constant and difference in air velocity in the large tube is small) so for the smallest particles the value of the eddy Stokes number is larger as shown in Table (2).

The effect of the dispersed phase on the turbulent kinetic energy is shown in Figs. 7 and 8 for different mass loading ratios and particles sizes. It was shown previously that the momentum exchange rate increases as mass loading ratio increases and particle size decreases. The momentum exchange between phases plays a major role in continues phase turbulence modulation. Therefore, the continues phase turbulent kinetic energy increases as particle size decreases or mass loading ratio increases, see Figs. 7 and 8 As the turbulence level increases, the mixing process downstream the sudden expansion is enhanced. 
Military Technical College

Kobry Elkobbah,

Cairo, Egypt

April 19-21,2016

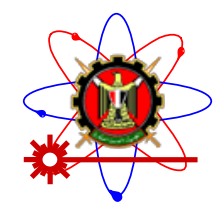

$8^{\text {th }}$ International Conference on Mathematics and Engineering Physics (ICMEP-8)

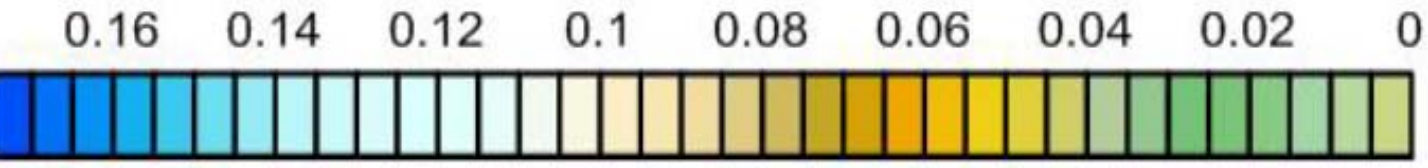

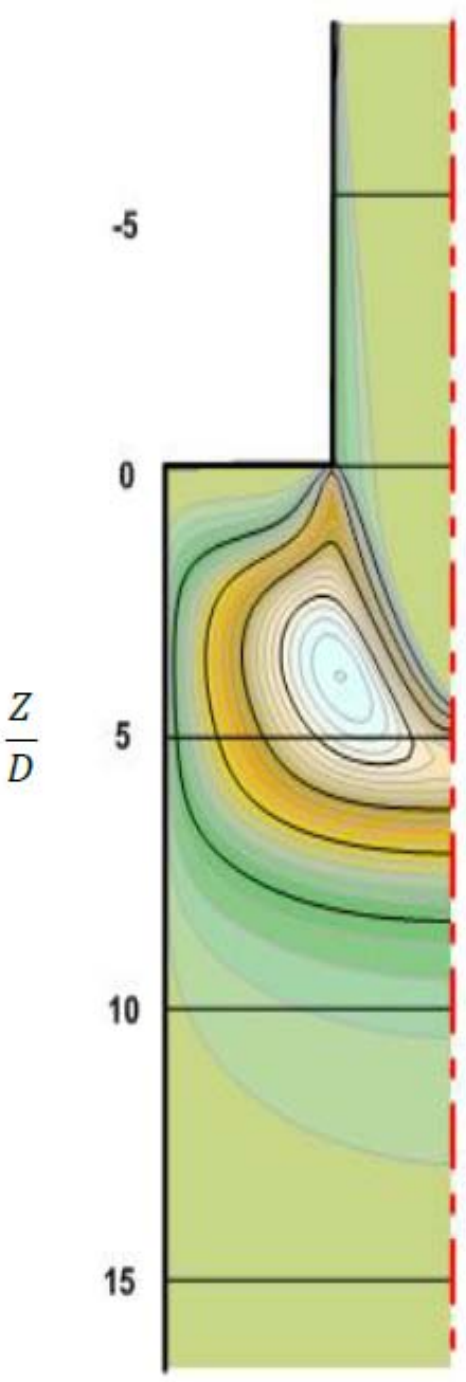

a) Single phase

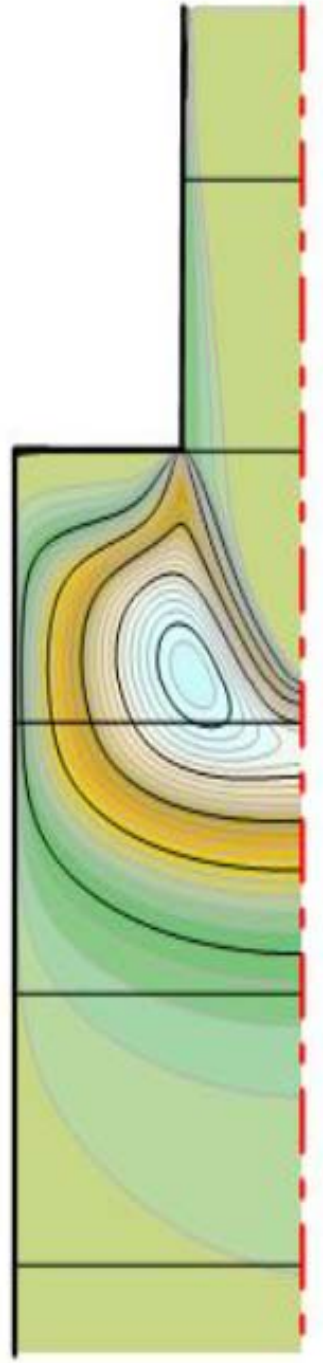

b) $\mathrm{MR}=0.2$

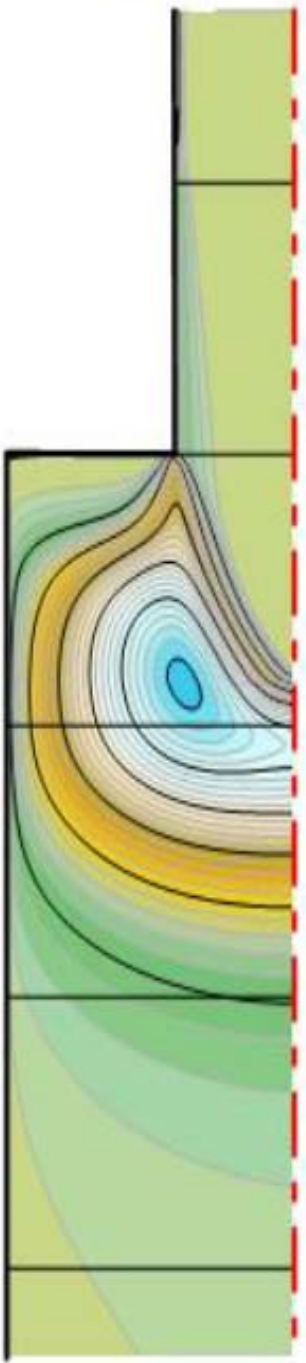

c) $\mathrm{MR}=0.5$

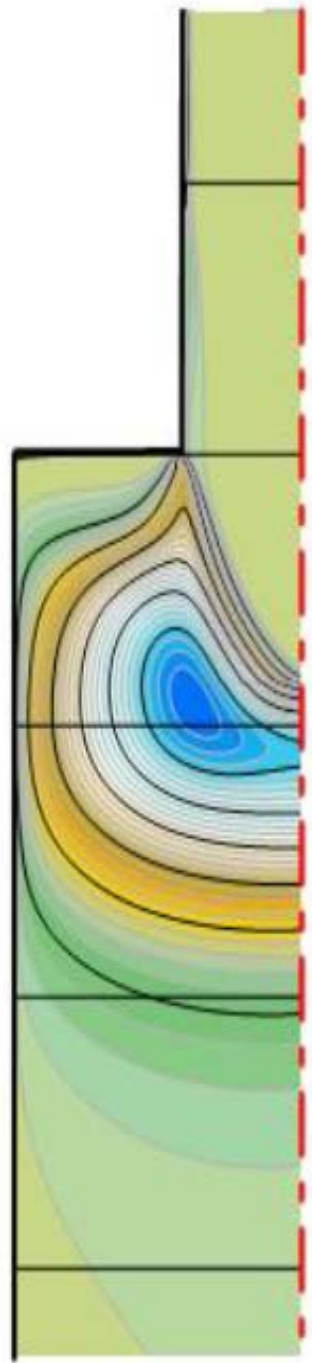

d) $\mathrm{MR}=1$

Figure (7) Effects of particle diameter on normalized turbulent kinetic energy $k / 0.5 u_{\text {in }}^{2}$ at

$$
\left(\mathrm{Re}=4 \times 10^{4}, D_{p}=50 \mu \mathrm{m} \text { and } A R=5.76\right)
$$


Military Technical College

Kobry Elkobbah,

Cairo, Egypt

April 19-21,2016

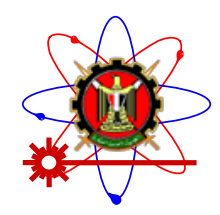

$8^{\text {th }}$ International Conference on Mathematics and Engineering Physics (ICMEP-8)

\begin{tabular}{c|c|c|c|c|c|c|c|c|c|c|c|c|c|c|c|c|}
\multicolumn{1}{c}{0.16} & \multicolumn{1}{c}{0.12} & \multicolumn{1}{c}{0.08} & 0.04 & \\
\hline
\end{tabular}

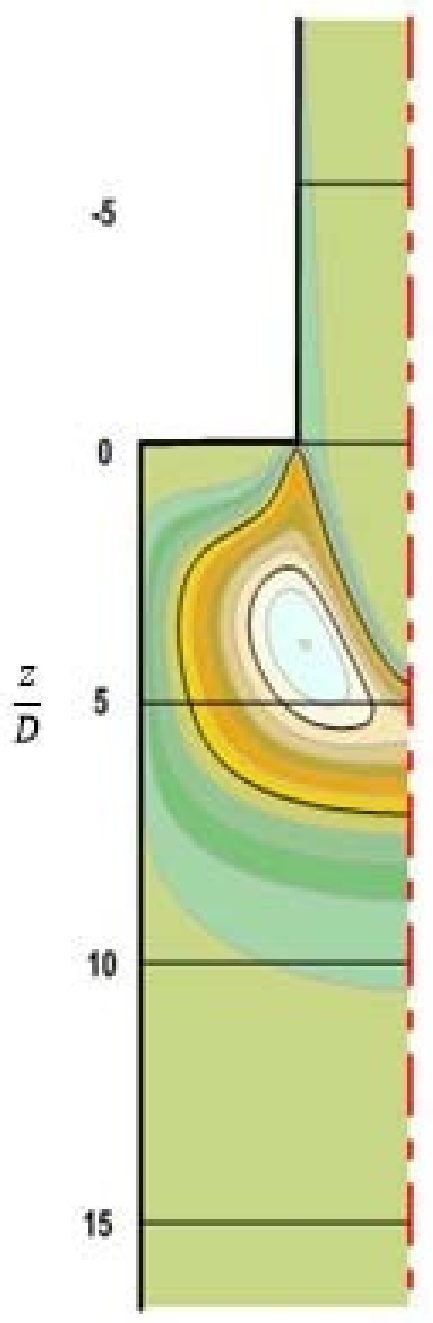

(a)Single phase

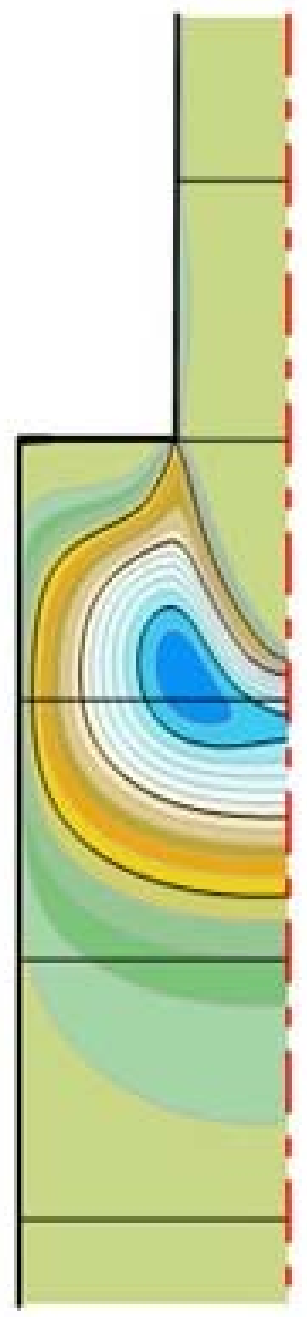

(b) $D_{p}=50 \mu \mathrm{m}$

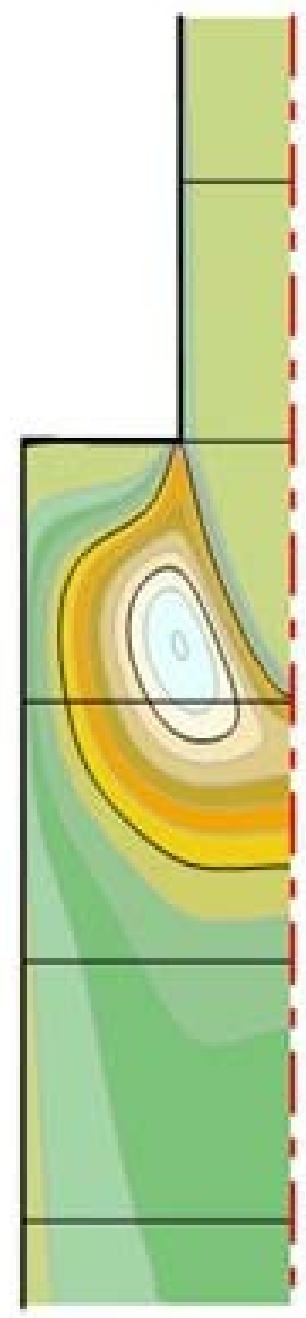

(c) $D_{p}=200 \mu \mathrm{m}$

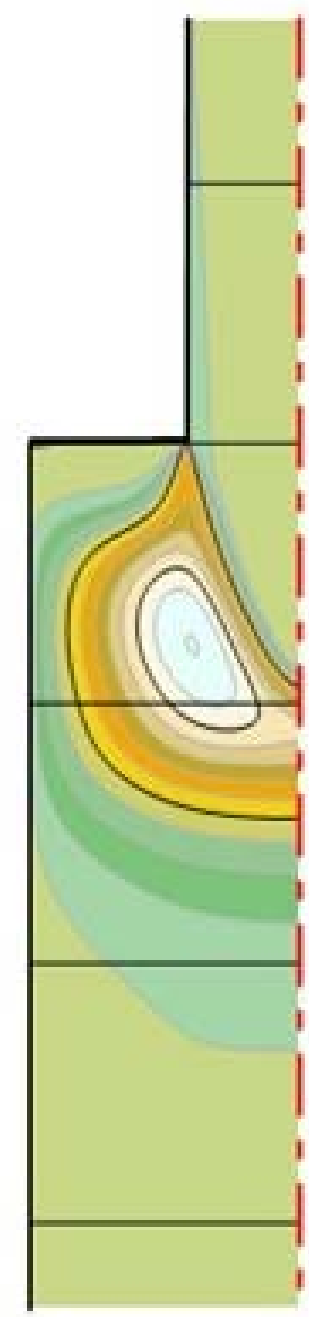

(d) $D_{p}=600 \mu m$

Figure (8) Effects of particle diameter on normalized turbulent kinetic energy $k / 0.5 u_{i n}^{2}$ at

$$
\left(\mathrm{Re}=4 \times 10^{4}, M R=1 \text { and } A R=5.76\right)
$$


Military Technical College

Kobry Elkobbah,

Cairo, Egypt

April 19-21,2016

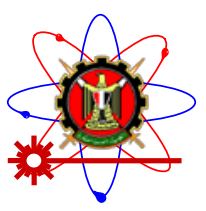

$8^{\text {th }}$ International Conference on

Mathematics and Engineering

Physics (ICMEP-8)

\section{Conclusions}

The performance of the sudden-expansion pipe is strongly affected by the presence of solid particles. The mass loading ratio plays a significant role in changing the turbulent kinetic energy where, the turbulent kinetic energy increases as the mass loading ratio increases. While the fine particles increases the turbulent kinetic energy. The presence of solid particles affects the size of separation bubble, as for the finest particles a bigger separation bubble is generated while increasing the solid particles sizes reduces the bubble size. This is due to ability of solid particles to entering in the separation zone.

However, a future extended study concerned with the effect of heat transfer on the performance of the sudden-expansion pipe for turbulent gas carrying solids will be taken into consideration. Non-linear turbulence model may be also considered to improve the computation performance.

\section{References}

[1] Abbot, D. E. and Kline, S. J., "Experimental investigation of subsonic turbulent flow over single and double backward facing steps ", Journal of Basic Engineering, Vol. 84 (3), pp. 317-325, 1962.

[2] Durst, F., Melling, A. and Whitelaw, J., H., "Low Reynolds number flow over a plane symmetrical sudden expansion", Journal of Fluid Mechanics; Vol. 64 (1), pp. 111-128, 1974.

[3] Chedron, W., Durst, F. and Whitelaw, J. H., "Asymmetric flows and instabilities in symmetric ducts with sudden expansions", Journal of Fluid Mechanics, Vol. 84 (1), pp. 13-31, 1978.

[4] Gould, R. D., Stevenson, W. H. and Thompson, H. D., "Investigation of turbulent transport in an axisymmetric sudden expansion", AIAA Journal, Vol. 28 (2), pp. 276-283, 1990.

[5] Durst, F., Pereira , J. C. F. and Tropea , C., "The plane symmetric sudden-expansion flow at low Reynolds numbers", Journal of Fluid Mechanics, Vol. 248, pp. 567- 581, 1993.

[6] Biswas, G., Breuer, M. and Durst, F., "Backward-facing step flows for various expansion ratios at low and moderate Reynolds numbers", Journal of Fluids Engineering, Vol. 126, pp. 362-374, 2004.

[7] Kumar, S., Chakrabarti, S. and Majumder, S., "Flow through a sudden expansion: a review", International Journal of Engineering and Science Research, Vol. 4 (4), pp. 167180, 2014.

[8] Durrett, R. P., Stevenson, W. H. and Thompson, H. D., "Radial and axial turbulent flow Measurements with an LDV in an axisymmetric sudden expansion air flow", Journal of Fluids Engineering, Vol. 110 (4), pp. 367-372, 1988.

[9] Kitoh, A., Sugawara, K., Yoshikawa, H. and Ota, T., "Expansion ratio effects on three- 
Military Technical College

Kobry Elkobbah,

Cairo, Egypt

April 19-21,2016

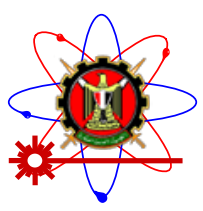

$8^{\text {th }}$ International Conference on

Mathematics and Engineering

Physics (ICMEP-8)

dimensional separated flow and heat transfer around backward-facing steps", Journal Heat Transfer, Vol. 129 (9), pp. 1141-1155, 2006.

[10] Okiy, K. V., "A comparative analysis of turbulence models utilized for the prediction of turbulent airflow through a sudden expansion", International Journal of Engineering

Research in Africa, Vol. 16, pp. 64-78, 2015.

[11] El-Askary, W. A., El-Mayet, M. and Balabel, A., "On the performance of suddenexpansion pipe without/with cross-flow injection: Experimental and numerical studies", International Journal for Numerical Methods in Fluids, Vol. 69, pp. 366-383, 2012

[12] Terekhov, V. I. and Pakhomov, M. A., "Turbulent gas-dispersed flow in a pipe with sudden expansion: numerical simulation" Thermophysics and Aeromechanics, Vol. 15 (4), pp. 589-601, 2008

[13] Mergheni, M. A., Sautet, J. C., Ben Ticha, H. and Ben Nasrallah, S., "Numerical simulation of sudden expansion particle laden flows using the Eulerian-Lagrangian approach", Thermal Science, Vol. 16 (4), pp. 1005-1012, 2008.

[14] Pakhomov, M. A. and Terekhov, V. I., "Comparison of the Eulerian and Lagrangian approaches in studying the flow pattern and heat transfer in a separated axisymmetric turbulent gas-droplet flow", Journal of Applied Mechanics and Technical Physics, Vol. 54 (4), pp. 596-607, 2013.

[15] Founti, M. and Klipfel, A., "Experimental and computational investigations of nearly dense two-phase sudden expansion flows", Experimental Thermal and Fluid Science Vol. 17, pp. 27-36, 1998.

[16] Xiangli, L., Sihao, L. and Yang L., "Effects of particle-particle collisions on sudden expansion gas-particle flows via a two-phase kinetic energy-particle temperature model", Advanced Powder Technology, Vol. 24, pp. 98-105, 2013

[17] Zhou, L., Liu, Y. and Xu, Y., "Measurement and simulation of the two phase velocity correlation in sudden-expansion gas-particle flow", Acta Mechanica Sinica., Vol. 27(4), pp. 494-501, 2011.

[18] Hardalupas, Y., Taylor, A. M., and Whitelaw, J. H., "Particle dispersion in a vertical round sudden-expansion flow", Philosophical Transactions: Physical Sciences and Engineering, Vol. 341 (1662), pp. 411-442, 1992.

[19] Deguchi, K., Tashiro, H., Jotaki, T. and Tomita, Y., "Sudden expansion of gas-solid two phase flow", Bulletin of JSME, Vol. 25 (200), pp 190-195, 1982.

[20] Tashiro, H. and Tomita, Y., "Sudden expansion of gas-solid two-phase flow in vertical downward flow", Bulletin of JSME, Vol. 27 (232), pp. 2160-2165, 1984.

[21] Tashiro, H. and Tomita, Y., "Sudden expansion of gas-solid two-phase flow in vertical upward Flow", Bulletin of JSME, Vol. 28 (245), pp. 2625-2629, 1985.

[22] Marjanovic, P., Levy, A. and Mason, D. J., "An investigation of the flow structure through abrupt enlargement of circular pipe", Powder Technology, Vol. 104 (3), pp. 296303, 1999.

[23] Gundogdu, M. Y., Kutlar, A. I. and Duz, H., "Analytical prediction of pressure loss through a sudden-expansion in two-phase pneumatic conveying lines", Advanced Powder Technology, Vol. 20, pp. 48-54, 2009.

[24] Yinpeng, L., Changjin, W. and Mingda, H., "Discussion on local resistance coefficient of 


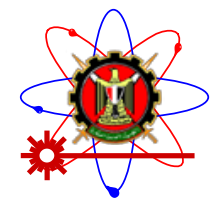

\section{$8^{\text {th }}$ International Conference on Mathematics and Engineering Physics (ICMEP-8)}

sudden expansion pipe", Journal of Applied Science and Engineering Innovation, Vol. 2 (2), pp. 37-39, 2015.

[25] Hamed, M. H., "Numerical simulation of gas-solid two- phase flow in a two-dimentional horizontal channel with sudden expansion", Alexandria Engineering Journal, Vol. 620 (4), pp. 435-453, 2006.

[26] El-Behery, S. M., El-Askary, W. A., Hamed, M. H. and Ibrahim, K. A., "Hydrodynamic and thermal fields analysis in gas-solid two-phase flow", International Journal of Heat and Fluid Flow, Vol. 32, pp. 740-754, 2011.

[27] Saffman, P.G, "The Lift on a small sphere in a slow shear flow" Journal of Fluid Mech. Vol. 22 (part 2), pp. 385-400, 1965.

[28] Mei, R., "An approximate expression for the shear lift force on a spherical particle at finite Reynolds number ", International Journal of Multiphase flow, Vol. 18, pp. 145-147, 1992.

[29] Lun, C. K. K and Liu, H. S., "Numerical simulation of dilute turbulent gas-solid flows in horizontal channels ", International Journal of Multiphase flow, Vol. 23, pp. 575-605, 1997.

[30] El-Askary, W. A., Ibrahim, K. A., El-Behery, S. M., Hamed, M. H. and Al-Agha , M. S., "Performance of vertical diffusers carrying gas-solid flow: experimental and numerical studies", Powder Technology, Vol. 273, pp. 19-32, 2015.

[31] Sommerfeld, M. and Huber, N., "Experimental analysis and modeling of particle-wall collisions", International Journal of Multiphase flow, Vol. 25, pp. 1457-1489, 1999.

[32] Heinl, E. and Bohent, M., "Calculation of particle-wall adhesion in horizontal gas-solid flow using CFD", Powder Technology, Vol. 159, pp. 95-104, 2005.

[33] Oesterle, B. and Petitjean, A., "Simulation of particle-to-particle interactions in gas solid flows", International Journal of Multiphase Flow, Vol. 19(1), pp. 199-211, 1993.

[34] Crowe, C., Sommerfeld, M. and Tsuji, Y., "Multiphase flow with droplets and particles ", CRC Press, Florida, USA, 1998.

[35] Eghlimi, A., Kouzoubov, A. and Fletcher, C.A.J., "A New RNG-based two-equation model for predicting turbulent gas-particle flows", International Conference on CFD in mineral \& Metal Processing and Power Generation, 1997

[36] El-Askary, W. A. and Balabel, A., " Prediction of reattaching turbulent shear flow in asymmetric divergent channel using linear and non-linear turbulent models", Engineering Research Journal (ERJ), Vol. 30(4), pp. 535-550, 2007.

[37] El-Behery, S. M. and Hamed, M. H., "A comparative study of turbulence models performance for separating flow in a planar asymmetric diffuser", Computers and Fluids, Vol. 44, pp. 248-257, 2011. 